\title{
DAMPING SPURIOUS HARMONIC RESONANCES IN THE APS STORAGE RING BEAM CHAMBER*
}

\author{
Y. Kang, G. Decker, and J. Song, ANL, Argonne, IL
}

\section{Abstract}

The APS storage ring beam chamber has been storing the beam up to $100 \mathrm{~mA}$ successfully. However, in some beam chambers, spurious signals corrupted the BPM outputs. The cause of the unwanted signals was investigated, and it was found that transverse electric (TE) longitudinal harmonic resonances of the beam chamber were responsible. The beam chambers have small height in the area between the oval beam chamber and the antechamber. The structure behaves like a ridge waveguide so that the cut-off frequency of the waveguide mode becomes lower. The pass-band then includes the frequency around $350 \mathrm{MHz}$ that is important to the beam position monitors (BPMs). The spurious harmonic resonances are damped with two types of dampers to restore the useful signals of the BPMs; coaxial loop dampers and lossy ceramic slab loading are used.

\section{INTRODUCTION}

Since the commissioning of the Advanced Photon Source in 1995, significant progress has been made in the area of beam stabilization [1,2]. A mystery that has only recently been solved was connected with the observation that systematic errors in beam position monitor (BPM) readbacks have historically been an order of magnitude greater for vertical readbacks than for horizontal. Considering that the BPM monopulse rf receiver electronics multiplexes between horizontal and vertical readings on alternate turns, and that the horizontal and vertical difference signals are computed in real time by if hybrids in the tunnel, it was difficult to attribute the observations to an electronics malfunction.

After a substantial effort to exonerate the electronics as the culprit, including various combinations of cable swapping, other causes were investigated. Among these was a suspected mechanical instability in the storage ring vacuum chamber (Figure 1). Certain misbehaving units demonstrated step-like behavior at the 150-micron scale. A dial indicator with remote camera display was used in several arrangements to show that the sudden step change in vertical BPM readback was not correlated with vertical vacuum chamber motion. At wit's end, a network analyzer was used to measure the transmission of $\mathrm{rf}$ power in the frequency band near the ring if frequency of $351.93 \mathrm{MHz}$, from one end of the suspect chamber to the other using the BPM pickup

\footnotetext{
Work suppored by U. S. Department of Energy, Office of Basic Energy
} Sciences under Contract No. W-31-109-ENG-38.

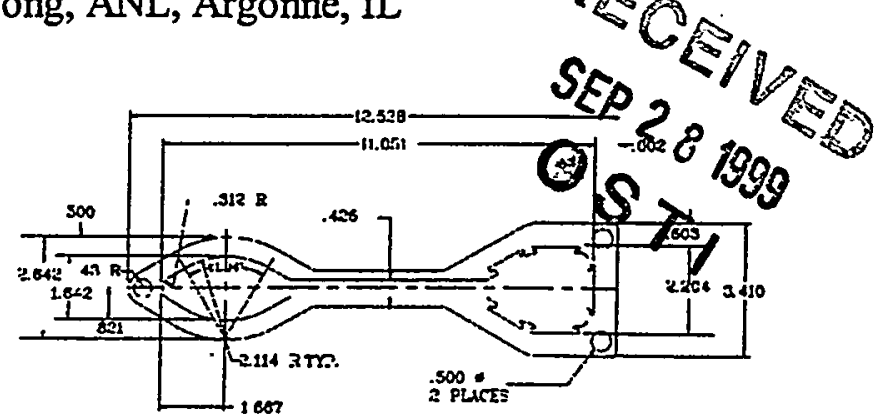

Figure 1: Storage ring vacuum chamber cross section (dimensions shown are inches)

electrodes mourited at opposite ends of the vacurum chamber. It has been known that the cut-off frequency for the storage ring vacuum chamber was above $1 \mathrm{GHz}$ for TM modes, well outside the $20-\mathrm{MHz}$ band centered on $352 \mathrm{MHz}$ where the if BPMs are sensitive. The result of the measurement, however, was that several resonance lines with Qs of the order of 1000 were discovered near $352 \mathrm{MHz}$. Simulations indicated that these "rogue" microwave modes were similar to TE01 waveguide modes. The electric field for these modes is oriented vertically with magnetic field lines circulating parallel to the beam in the beam chamber (the left-hand portion of Figure 1) and returning back on the right hand portion of the chamber (the antechamber), where nonevaporable getter $(\mathrm{NeG})$ vacuum pumping strips are mounted. The vertical electric field orientation explained why only vertical BPM readbacks were affected.

The chamber design and rf analysis for beam-induced transverse magnetic (TM) modes appeared in Refs. [3][4]. Because the beam chamber and antechamber are connected through a narrow channel with a small height, the vacuum chamber resembles a ridged waveguide. The area with a small height introduces a large capacitive loading that lowers the cut-off frequency for TE01-like modes of the chamber in comparison to a rectangular waveguide having the same width.

Investigations of damping systems to suppress the unwanted resonances in the chambers without major mechanical modification were conducted. Computer simulations and bench measurements were made to find an optimal solution. The use of matched load terminated coaxial loop antennas, lossy ceramic tiles, and the introduction of shorting bars inside chambers were considered. Because shorting bars would intercept synchrotron radiation and require cooling, only the coaxial dampers and lossy ceramics were tested. Measurements with beam were conducted using the coaxial damper option. 


\section{DISCLAIMER}

This report was prepared as an account of work sponsored by an agency of the United States Government. Neither the United States Government nor any agency thereof, nor any of their employees, make any warranty, express or implied, or assumes any legal liability or responsibility for the accuracy, completeness, or usefuiness of any information, apparatus, product, or process disclosed, or represents that its use would not infringe privately owned rights. Reference herein to any specific commercial product, process, or service by trade name, trademark, manufacturer, or otherwise does not necessarily constitute or imply its endorsement, recommendation, or favoring by the United States Government or any agency thereof. The views and opinions of authors expressed herein do not necessarily state or reflect those of the United States Government or any agency thereof. 


\section{DISCLAIMER}

Portions of this document may be illegible in electronic image products. Images are produced from the best available original document. 


\section{SIMULATION}

The wavelength in a hollow waveguide satisfies the relationship:

$$
f=c\left[1+\left(\lambda_{g} / \lambda_{c}\right)^{2}\right]^{1 / 2} / \lambda_{g}
$$

where $c$ is the speed of light in free space, $\lambda_{c}$ is the cutoff wavelength, and $\lambda_{g}$ is waveguide wavelength. Using chamber length $L=4.81 \mathrm{~m}$ and $\lambda_{\mathrm{g}}=2 \mathrm{~L} / \mathrm{N}(\mathrm{N}=1,2,3 \ldots .$.$) ,$ the resonance frequencies can be estimated. The chambers showing the largest effect are slightly curved, and are installed in the gap of the storage ring dipole magnets. The first resonance is the one closest to the cut-off frequency of the waveguide. The waveguide wavelengths for these lower-order modes are much longer than free space wavelengths.

A MAFLA code simulation was used for the chamber model to check the harmonic resonances and ensure the damping schemes worked properly. Table 1 lists the first ten excited resonances in the chamber. The structure was approximated as a straight chamber since the curvature is small compared to the chamber's bending radius. The NeG strips were not included in the simulations. The results show that the frequency spacing increases as predicted above. Three matched-load coaxial probes mounted in the antechamber (right-hand side of Figure 1) using loop antennae mounted in existing vacuum ports were simulated with results also shown in Table 1.

Table 1: Calculated resonance frequencies and Q-factors of the chamber modes without and with the coaxial dampers

\begin{tabular}{|c|c|c|c|c|}
\hline & \multicolumn{2}{|c|}{ Bare Chamber } & \multicolumn{2}{c|}{$\begin{array}{c}\text { With Three Coaxial } \\
\text { Dampers }\end{array}$} \\
\hline$\#$ & $\begin{array}{c}\text { Freq } \\
(\mathbf{M H z})\end{array}$ & $\mathbf{Q}$ & $\begin{array}{c}\text { Freq } \\
(\mathbf{M H z})\end{array}$ & $\mathbf{Q}$ \\
\hline 1 & 324.0 & 3846 & 310.4 & 351 \\
\hline 2 & 328.3 & 3931 & 313.9 & 249 \\
\hline 3 & 335.3 & 4019 & 323.3 & 718 \\
\hline 4 & 345.0 & 4193 & 332.6 & 390 \\
\hline 5 & 356.9 & 4339 & 343.2 & 186 \\
\hline 6 & 371.1 & 4544 & 357.7 & 202 \\
\hline 7 & 387.1 & 4743 & 373.6 & 221 \\
\hline 8 & 404.8 & 4909 & 390.7 & 120 \\
\hline 9 & 424.0 & 5117 & 407.7 & 65 \\
\hline 10 & 444.5 & 5320 & 426.5 & 108 \\
\hline
\end{tabular}

The simulation showed that damping with coaxial probes can be a factor of -10 at around $350 \mathrm{MHz}$. This was considered helpful but not sufficient to eliminate the problem. Therefore, slabs of if absorbing material were used in the chamber slot area for further damping. Simulations were made with the ceramic material to see the damping performance and to optimize the position of the slabs inside the chamber.

Table 2 gives calculated resonance frequencies and $Q$ factors for chamber modes in the presence of a $5 \mathrm{~cm} \times 5$ $\mathrm{mm} \times 25 \mathrm{~cm}$ slab of lossy dielectric material placed in the "slot" region of a vacuum chamber at a distance $d$ from the upstream end. This portion of the vacuum chamber is "shadowed" from synchrotron radiation. Note that the calculated Q-factors become very low and do not depend strongly on the dimension $d$. Since the ceramic damping dominates, the addition of coaxial dampers makes very little difference. Also note that the lower mode frequencies become even lower with the ceramic slab loading.

Table 2: Calculated chamber resonance frequencies and $Q$ factors in the presence of lossy dielectric slabs

\begin{tabular}{|c|c|c|c|c|}
\hline & \multicolumn{2}{|c|}{$\begin{array}{c}\text { Ceramic Damper, } \\
d=0.25 m\end{array}$} & \multicolumn{2}{c|}{$\begin{array}{r}\text { Ceramic Damper } \\
d=0.5 m\end{array}$} \\
\hline$\#$ & $\begin{array}{c}\text { Freq } \\
(\mathbf{M H z})\end{array}$ & Q & $\begin{array}{c}\text { Freq } \\
(\mathrm{MHz})\end{array}$ & Q \\
\hline 1 & 132.6 & 2.7 & 131.7 & 2.8 \\
\hline 2 & 226.8 & 2.8 & 225.2 & 3.0 \\
\hline 3 & 327.5 & 144.5 & 327.6 & 54.0 \\
\hline 4 & 331.8 & 13.2 & 3312 & 5.86 \\
\hline 5 & 335.9 & 5.3 & 335.3 & 9.3 \\
\hline 6 & 342.7 & 18.5 & 344.3 & 36.0 \\
\hline 7 & 353.9 & 51.8 & 357.0 & 74.7 \\
\hline 8 & 368.1 & 86.7 & 372.7 & 103.3 \\
\hline 9 & 384.6 & 102.5 & 391.0 & 95.7 \\
\hline 10 & 4032 & 81.5 & 410.7 & 37.8 \\
\hline
\end{tabular}

The rf absorbing material was chosen to be vacuum compatible, stable, and efficient for damping. Good thermal conductivity was also desired. A few different types of lossy dielectric material were considered. Aluminum nitrite (AIN) with a high content of silicone carbide ( $\mathrm{SiC}$ ) was chosen for its properties that satisfy the above requirements. The most important material properties for our application are summarized in Table 3.

Table 3: Mechanical and electrical properties of the ceramic, AlN with $40 \% \mathrm{SiC}$

\begin{tabular}{|l|c|}
\hline Thermal Conductivity $\left(\mathrm{W} / \mathrm{m}^{\circ} \mathrm{K}\right)$ & 120 \\
\hline Expansion Coefficient $\left(10^{-6} / \mathrm{C}\right)$ & $\sim 4$ \\
\hline Dielectric Constant $\left(\varepsilon_{\mathrm{r}}\right)$ & $\sim 30$ \\
\hline Loss Tangent $(\tan \delta)$ & $\sim 0.4$ \\
\hline
\end{tabular}

\section{MEASUREMENT}

Resonance frequencies and $\mathrm{Q}$ factors in a spare beam chamber were measured and compared with the simulation values shown in Table 1 . The measurement was repeated with the addition of coaxial dampers on the 1.4 " antechamber ports of the spare chamber. A vector network analyzer was used to measure transmission between BPM pickup electrodes mounted at opposite ends of the chamber. A four-channel rf 180-degree ratrace hybrid was used at one end of the chamber to drive the top two button pickups out of phase from the bottom two, coupling to the vertical electric field. The transmission coefficient $S_{21}$ from the hybrid "vertical" port to a single button at the opposite chamber end is 
shown in Figures 2 and 3. The peaks of the coupled modes are not constant since the coupling of the different modes to the BPM buttons is not uniform.

Note that the calculated $Q$ factors are much higher than the measured values shown in Figure 2. A possible explanation is that the NeG strips were not included in the model. The NeG strips are located in the antechamber where the magnetic field dominates so that the surface loss becomes greater, damping the resonances significantly. Figure 3 shows the same measurement with two coaxial dampers mounted in the antechamber.

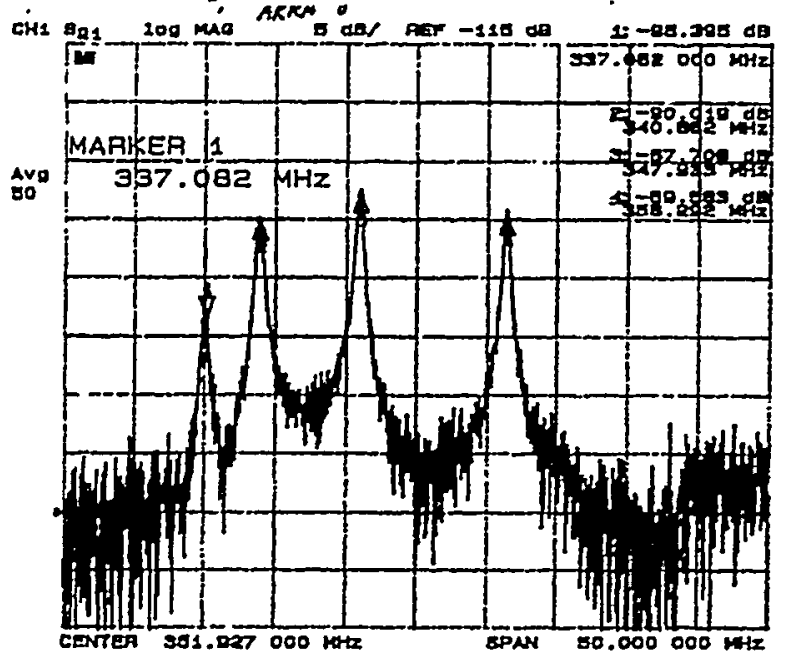

Figure 2: Resonances in a chamber with NeG strips

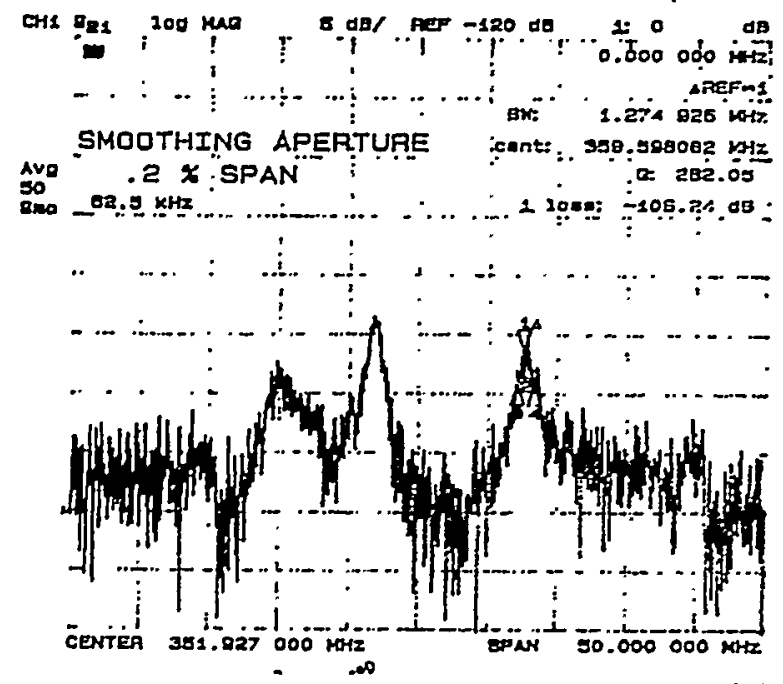

Figure 3: Resonances in a chamber with two coaxial dampers and NeG strips

Shown in Figure 4 is a single-bunch beam spectrum taken from the vertical difference output of a fourchannel rf hybrid connected at a BPM pickup location where this mode was causing severe problems.

A single bunch was used because of its extremely simple spectrum, namely a series of uniformly spaced spectral lines of equal amplitude, with $271-\mathrm{kHz}$ spacing (the APS revolution frequency). The two data sets shown in Figure 4 were collected five months apart, the control set (top) employing a broad-band hybrid, while the "after" data set (bottom) used the standard BPM hybrid that includes a $20-\mathrm{MHz}$ bandwidth bandpass filter on the output. The degree to which the spectral lines in the broad-band data differ in amplitude is a measure of the impact of the chamber resonance. The feature centered near the 352-MHz of frequency was responsible for pathological BPM behavior and was substantially suppressed by the single probe installed (the other available vacuum ports on that chamber were being used for vacuum diagnostics).
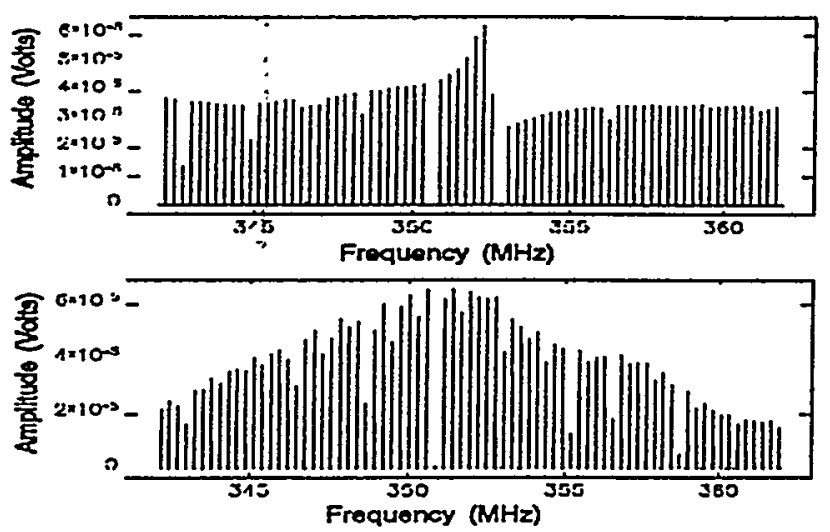

Figure 4: BPM signal without dampers (top), and with one coaxial damper (bottom, $20 \mathrm{MHz}$ band limited)

\section{CONCLUSIONS}

A set of microwave modes that are present in APS vacuum chambers and have significant impact on vertical BPM performance have been discovered. Solutions to damp these modes include coaxial dampers and the introduction of lossy dielectric material. The coaxial damper solution has been successfully employed with beam; however, the lossy dielectric approach promises better damping of more modes. Research into viable installation configurations is ongoing.

\section{ACKNOWLEDGEMENT}

Authors are thankful to J. Galayda, Accelerator Systems Division Director of the APS, for his direction and encouragement on the investigation of the problem.

\section{REFERENCES}

[1] G. Decker et al., "Fundamental Limits on Beam Stability at the APS," BIW'98, AIP 451, pp. 237-244 (1998).

[2] J. Carwardine and F. R. Lenkszus, "Real-Time Orbit Feedback at the APS," BIW'98, AIP 451, pp. 125-144 (1998).

[3] R. Wehrle et al., "Vacuum System for the Synchrotron X-ray Source at Argonne," Proc. 1987 IEEE PAC, Washington D.C., pp. 16691671 (1987).

[4] R. Kustom et al., "Analysis of if Modes in the ANL APS Vacuum Chamber Using Computer Simulation. Electron Beam Excitation, and Perturbation Techniques," Proc. 1989 IEEE PAC. pp. 17551757 (1989). 